\title{
Positioning the goalposts
}

The best environmental policy depends on how you frame the question.

\section{John Maddox}

s sustainability sustainable? We are all environmentalists now, of course, and since the Brundtland report in 1992 we have hewn to the doctrine that the only good, or even permissible, changes in the Earth's surface and the uses we make of it are 'sustainable'. Exactly what sustainable development means is, unfortunately, not crystal clear. On the strictest reading, the burning of a single tonne of fossil fuel would be banned, because the result would be that coal and petroleum reserves were less easily accessible to future generations, leading to the conclusion that the only permissible energy sources are renewable Sun, wind and water.

Not even Greenpeace or Friends of the Earth go quite as far as to advocate an immediate shut-down of the fossil-fuel industries. It is not practical politics. In any case, this strict reading of sustainability leads directly to a paradox: it would deny to future as well as present generations the exploitation of any finite resource, meaning that future generations would be no worse off if the resource had already been consumed by the time they came on the scene. One way round that difficulty is to relax the reading of sustainability.

Petroleum, for example, now sells at $\$ 22$ a barrel, so we can claim that we are exploiting only the reserves whose production cost is less than that. So far as we know (for the oil companies have no incentive to look for uneconomic reserves), there will be plenty of $\$ 30$-a-barrel oil left in the ground a decade hence. We cannot now know whether future generations will be able to afford steadily rising oil prices, of course. The market will in any case decree that the cheapest source of energy be exploited first.

Either the next generation will pay $\$ 30$ a barrel for oil, or it will use renewables or nuclear energy. Either way, loosening the definition of sustainability entails the exhaustion of current resources and their replacement by others. How long can that continue? The missing ingredient in all arguments about sustainability is that there is no agreement about long-term goals - or even on what is meant by 'long' term. The two questions are inseparable and inevitably in conflict, and for a simple reason.

To a large degree, Homo sapiens has opted out of the tyranny of natural selection, often for the best compassionate reasons. Since the beginning of civilization, we have protected ourselves against the elements by building shelters and have fed ourselves by growing

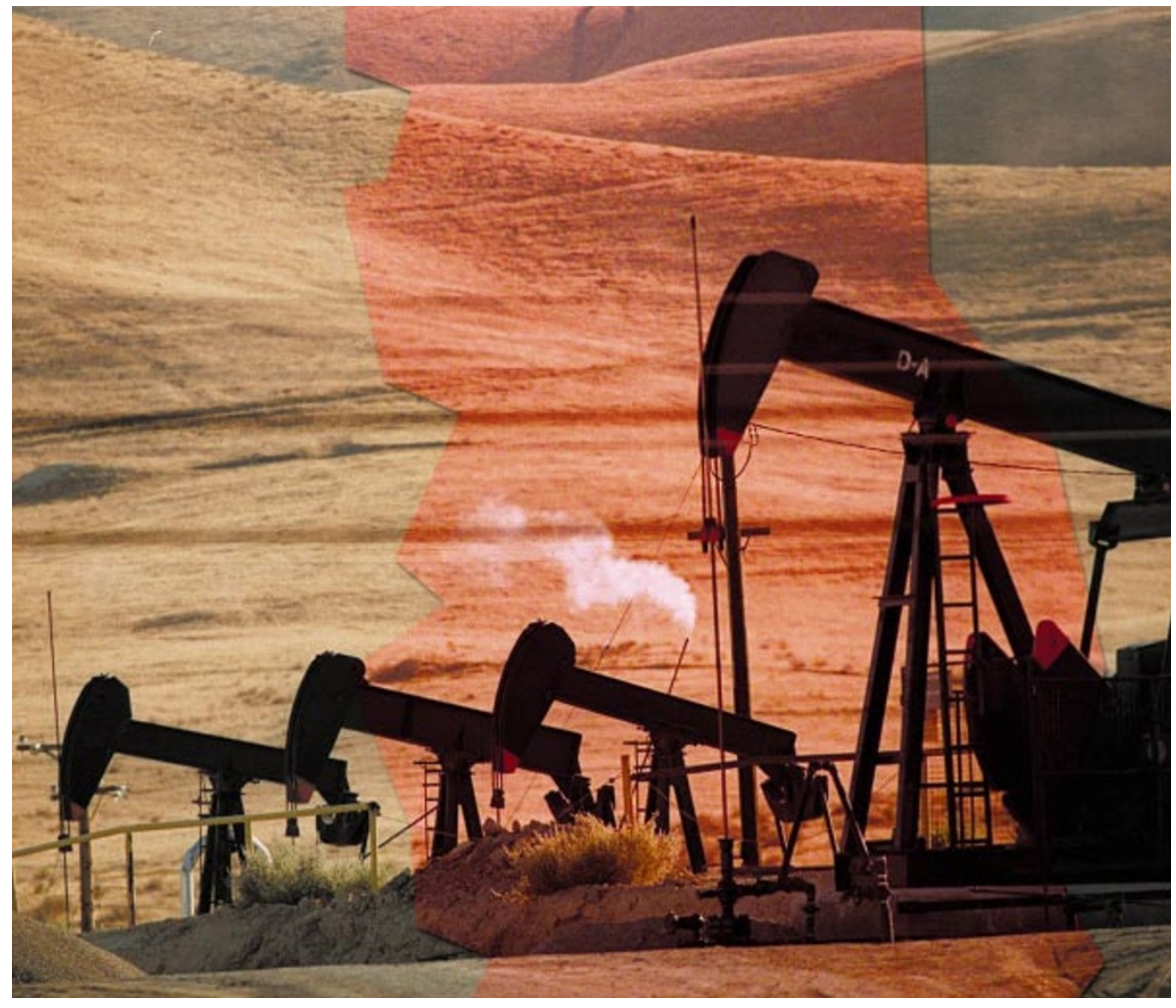

Here today: there is no general agreement about the meaning or timescale of sustainable development.

crops and herding domesticated animals, transforming the ecology of large tracts of the Earth's surface in the process. Now we offer infants paediatric medicine and do what can be done to avoid the deaths of adults, even those beyond reproductive age. One consequence is that the human population (now in excess of 6 billion people) is much greater than that of comparable animals at the tops of food chains - whales or tigers, for example. Another is that welfare rolls are growing in many countries, rich countries in particular. A third is pollution on a global scale, such as the accumulation of atmospheric carbon dioxide.

Responding to such problems requires prior decisions on objectives. Should global policy aim at the indefinite preservation of the human race, as seems to have been implicit in human behaviour since the first human settlements 5,000 years ago? And, if so, does that mean the survival of 6 billion people or some other number? And do we aim to hold to the goal for another century, for a millennium, until the Sun becomes a red giant or even for the rest of time?

It would be simplest if none of these questions required an immediate answer. Even if, as seems probable, the Intergovernmental Panel on Climate Change has exaggerated the impending rate of temperature increase by a factor of two, our misfortune is that some kind of determination will probably be necessary in the next century or so. If the objective is the survival of the human race, we would surely be spending more on carbon dioxide abatement, less on biodiversity and a lot more than we do at present on avoiding asteroid impacts with the Earth. If survival beyond the red-giant phase of the Sun is taken seriously, Mars would be colonized sooner than would otherwise be prudent.

The pity is that there is no forum in which these matters can be discussed, let alone decided. But this is probably just as well. The admirable United Nations is good at making compromises, but they are usually expensive - so expensive that they drain funds from other urgent tasks. And the obvious determinations of the key questions of whether the survival of the human race should be our goal, and whether the timescale is indefinitely long, provoke illiberal solutions - eugenics for all at the very least.

So we must fall back on the old-fashioned remedy of public argument and controversy. It is to be hoped that the next millennium, even the next century, will see the need.

Sir John Maddox is Emeritus Editor of Nature and is at 9 Pitt Street, London W8 4NX, UK. 